\title{
Effect of cyclic wetting-drying on tensile mechanical behavior and microstructure of clay-bearing sandstone
}

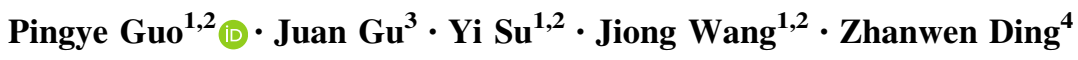

Received: 24 August 2020/Revised: 25 October 2020/Accepted: 26 December 2020/Published online: 2 February 2021

(C) The Author(s) 2021

\begin{abstract}
The understanding of the weakening mechanism of tensile strength of rock subjected to cyclic wetting-drying is critical for rock engineering. Tensile strength tests were conducted on a total of 35 sandstone specimens with different wetting-drying cycles. The crack propagation process and acoustic emission characteristics of the tested samples were obtained through a high-speed camera and acoustic emission system. The results indicate that the tensile strength is observably reduced after cyclic wetting-drying, and the extent of the reduction is not only related to the number of wettingdrying cycle, but also closely related to the clay mineral content of the sample. In addition, as the cycles of wetting-drying increase, the effect of each single cycle on tensile strength get reduced until it becomes constant. Moreover, the crack initiation and penetration time is prolonged as the number of wetting-drying cycle increases, which indicates that cyclic wetting-drying weakens the rock stiffness and enhances the ductility of sandstone. Meanwhile, the acoustic emission characteristics of the tested samples further confirmed the ductile behaviour of the sandstone samples with increasing wetting-drying cycle. Furthermore, through the analysis of the microstructure and mineral composition of the samples with different wetting-drying cycles, it is concluded that the main weakening mechanisms of sandstones containing clay minerals are frictional reduction, chemical and corrosive deterioration.
\end{abstract}

Keywords Sandstone $\cdot$ Wetting-drying cycle $\cdot$ Tensile strength $\cdot$ Weakening mechanism $\cdot$ Failure characteristics

\section{Introduction}

Many rocks in nature and rock engineering are subject to cyclic wetting-drying, such as rock in pumping reservoirs, coastlines, exposed slopes, etc. (Yang et al. 2017; Han

Jiong Wang

wangjiong0216@163.com

1 State Key Laboratory for Geo-Mechanics and Deep Underground Engineering, Beijing 100083, China

2 School of Mechanics, Architecture and Civil Engineering, China University of Mining and Technology, Beijing 100083, China

3 Tang Steel International Engineering Technology Corp, Tangshan 063000, China

4 China Henan Geological and Mineral Resources Construction Engineering (Group) Co., Ltd, Zhengzhou 450007, China et al. 2016; Duda and Renner 2013). The mechanical properties of rock are highly susceptible to deteriorate under the influence of cyclic wetting-drying, which is the cause of many engineering disasters (Zhao et al. 2017b, a; Pudlo et al. 2012). Therefore, understanding the effects of cyclic wetting-drying on mechanical behavior of rock is critical to rock engineering in reality. An impressive number of papers have been published in recent years addressing the subject of the effects of water-rock interaction on mechanical behavior of various rocks (Mann and Fatt 1960; Baud et al. 2000; Hale and Shakoor 2003; Vásárhelyi and Ván 2006; Doostmohammadi et al. 2009; Özbek 2014; Yang et al. 2019). Previous studies have shown that the mechanism of water-rock interaction that leads to the weakening of strength mainly includes fracture energy reduction, capillary tension decrease, pore pressure increase, fractional reduction, and chemical and corrosive 
deterioration (Yilmaz 2010; Karakul and Ulusay 2013; Wong et al. 2015; Momeni et al. 2017; Wu et al. 2018; Eang et al. 2018).

In addition to the mechanical behavior of rock under uniaxial and triaxial conditions, substantial research efforts have recently been focusing on the effects of water-rock interaction on the mechanical behavior under tensile conditions (Fu et al 2017; Huang et al. 2010), especially under the state of cyclic wetting-drying. For example, the fracture behavior of rock in different water conditions has been investigated, and results show that water has weakened fracture toughness and stiffness of sandstone (Hua et al. 2015; Zhou et al. 2018a, b). It was found that the cyclic wetting-drying has an influence on the crack propagation, fracture toughness and stiffness of sandstone. Through the experimental research on artificial gypsum, it is found that the tensile strength of wet gypsum is about $50 \%$ lower than that of dry gypsum, but the strength under different soaking duration is not much different, and it is also found that the effect of water-rock interaction has a great influence on the development of crack (Wong and Jong 2014). For sandstone with a low clay mineral content, experimental result shows that the tensile strength is affected by the water state of the rock, but is probably not sensitive to the length of immersion, and that cyclic wetting-drying does not necessarily reduce the tensile strength permanently. The major water-weakening mechanisms are reductions in the fracture energy and the fraction coefficient (Zhao et al. 2017a, b; Song et al. 2019a, b; Ma et al. 2018). As regards the limestone with clay minerals, it is found that the clay mineral content directly affects the weakening effect of water against tensile and compressive stress (Cherblanc et al. 2016). Moreover, the effect of cyclic drying and wetting on the dynamic tensile strength of rock is discussed, and a decay model considering the loading rate and the influence of cyclic drying and wetting was proposed (Zhou et al. 2016; Zhou et al. 2018a, b). Wetting-drying cycle can cause cyclic expansion and contraction of hydrophilic clay minerals in soil, induce expansion to repeatedly act on soil microstructure, resulting in fatigue damage, leading to sudden reduction of soil cohesion; matrix suction growth during dehumidification, pore wall expansion during moisture absorption, decomposition and loss of cement will reduce soil strength (Liu et al. 2020; An et al. 2020).

Despite the extensive and outstanding research, most of which indicates that the cyclic wetting-drying weakens the tensile strength of rock, the mechanism of weakening is not still clear. Regarding sandstones containing clay minerals in particular, the effect of the number of wetting-drying cycles on the tensile mechanical behavior of the rock, and how the cyclic wetting-drying changes the microstructure of rock and affects the macroscopic mechanical properties, remain unclear. Therefore, in this study, the cracking and failure processes in tension of sandstone containing clay minerals subjected to different number of wetting-drying cycles was investigated using high speed camera and acoustic emission (AE). Meanwhile, the mineralogical composition and microstructure of specimens under different number of wetting-drying cycles were analyzed using X-ray diffraction and Scanning Electron Microscope (SEM). Moreover, the mechanism of the influence of cyclic wetting-drying on rock mechanical behavior is discussed.

\section{Materials and methods}

\subsection{Sample preparation and experimental procedure}

All sandstone samples in this experiment were collected from Dianping Mine in Lvliang City, Shanxi Province, China. In order to reduce the discreteness of samples, all samples were extracted from sandstone of the same stratum. According to the recommendations of the International Society for Rock Mechanics (ISRM 1978), the samples were cut into discs of $50 \mathrm{~mm}$ in diameter and $25 \mathrm{~mm}$ in thickness. As shown in Fig. 1a, 35 samples in total were divided into 7 groups according to the number of wetting-drying cycles. The 7 groups of samples were respectively subjected to $0,2,4,10,20,30$, and 40 wetting-drying cycles. Each cycle of wetting-drying treatment was achieved by oven-drying at $105^{\circ} \mathrm{C}$ for $12 \mathrm{~h}$ and airdrying at room temperature $25{ }^{\circ} \mathrm{C}$ for $12 \mathrm{~h}$, immersing the samples in a vacuum of less than $800 \mathrm{~Pa}$ for $24 \mathrm{~h}$ until saturation (ASTM 2008).After consulting books and other materials, high temperature has an obvious impact on rock mechanical properties. The laboratory drying oven is $105^{\circ} \mathrm{C}$, and the temperature of drying oven is also common in other literatures. In order to prevent the influence of ions in the water on the properties of the rock, the soaked water is deionized. The basic physical parameters of each group of samples are shown in Table 1. The density of the seven groups of wet saturated samples in the final state were measured after different cycles. The experimental procedure has an element of result discussion even before the experimental setup in Sect. 2.2. The results show that the density is slightly reduced after multiple wetting-drying cycles, but the regularity is not obvious. It can be seen from Table 1 that the variation of the S-wave velocity with the times of wetting-drying cycles is not obvious, and the $\mathrm{P}$-wave velocity increases significantly with the increase of the times of wetting-drying cycles. The wave velocity is measured under the wet and saturated condition after the dry and wet cycles. The effect of water on the acoustic velocity of rock is mainly to fill the subtle cracks and pores 


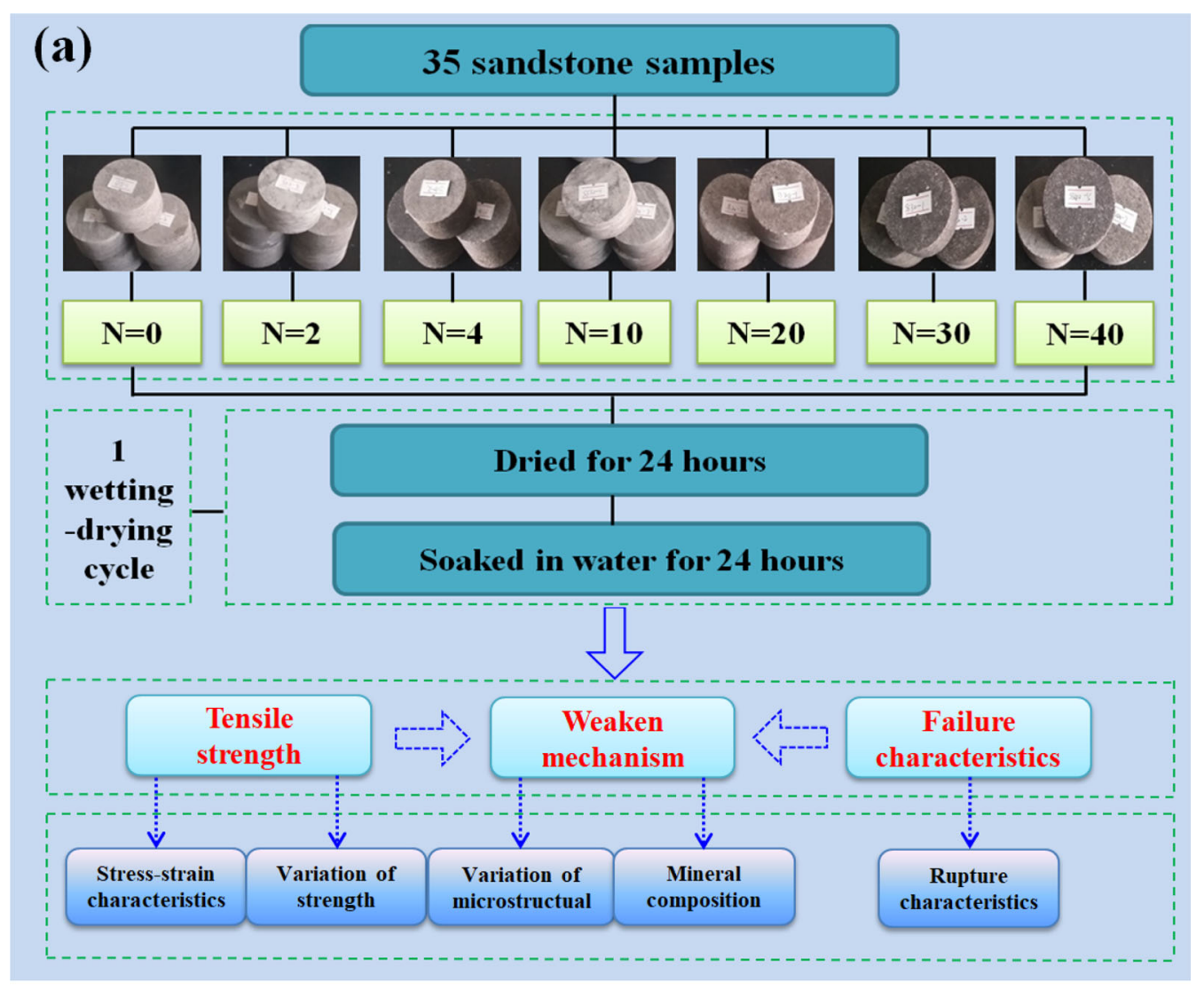

(b)

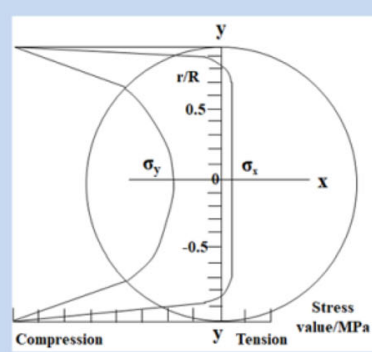

Schematic diagram of stress distribution

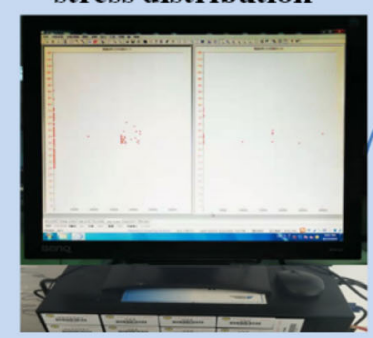

Acoustic emission system

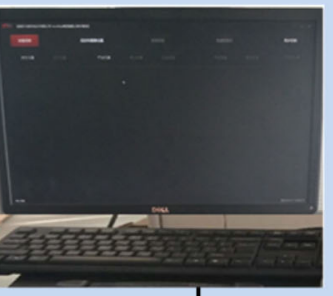

High speed camera

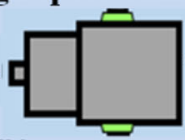

Sandstone

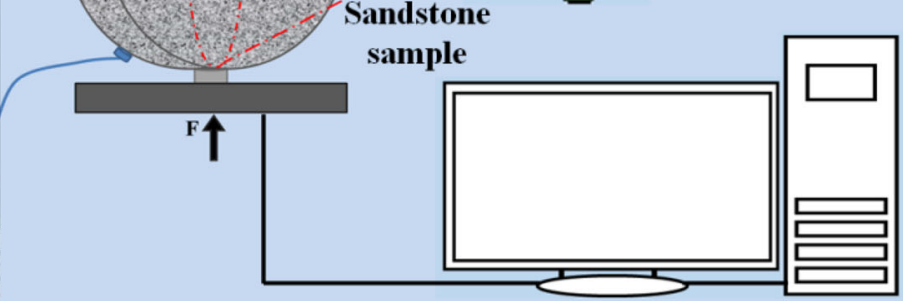

Control system

Fig. 1 Experimental procedure and setup. a Block diagram of experiment; b Schematic diagram of experimental equipment 
Table 1 Physical property of sandstone samples

\begin{tabular}{|c|c|c|c|c|}
\hline Number of cycles & $\begin{array}{l}\text { Average } \\
\text { density } / \mathrm{cm}^{3}\end{array}$ & $\begin{array}{l}\text { Average } \\
\mathrm{S} \text { wave } \\
\left(\mathrm{km} / \mathrm{s}^{1}\right.\end{array}$ & $\begin{array}{l}\text { Average } \\
\mathrm{P} \text { wave } \\
\left(\mathrm{km} / \mathrm{s}^{1}\right)\end{array}$ & Porosity \\
\hline 0 & 2.585 & 2.122 & 1.876 & 3.83 \\
\hline 2 & 2.549 & 1.893 & 1.849 & 4.89 \\
\hline 4 & 2.442 & 2.355 & 1.976 & 6.29 \\
\hline 10 & 2.415 & 1.987 & 1.729 & 7.96 \\
\hline 20 & 2.488 & 3.147 & 2.658 & 4.58 \\
\hline 30 & 2.513 & 3.292 & 2.714 & 2.53 \\
\hline 40 & 2.509 & 3.498 & 2.822 & 7.88 \\
\hline
\end{tabular}

(Liu et al. 2016), so it will increase accordingly. For the porosity test results, the porosity values increased with increasing wetting-drying cycles before the ten (10) wetting-drying cycle and change in this trend after 10th cycle was not obvious.

In this work, Brazilian tensile tests were performed in the wet saturated state after the samples had experienced 0 , $2,4,10,20,30$ and 40 wetting-drying cycles. As shown in Fig. 1a, there are mainly three targets of the experimental observation: (1) the stress-strain curve and the variation of the tensile strength with respect to the number of wettingdrying cycles; (2) the crack propagation process and the variation of the acoustic emission characteristics with respect to the number of wetting-drying cycles; (3) the microstructure and mineral composition of the sample variation with respect to the number of wetting-drying cycles.

\subsection{Experimental setup}

The system diagram of the experimental setup is shown in Fig. 1b. It can be seen that the experimental system mainly includes the following parts: (1) a loading system; (2) a high-speed photography system; (3) an acoustic emission system. In the Brazilian splitting test, a vertical loading rate of $0.5 \mathrm{~mm} / \mathrm{min}$ was applied to the samples. Throughout the experiment, the generation and propagation of crack was recorded in real time by the high-speed camera in front of samples. Meanwhile, the AE system was used to monitor the precursor of sample rupture. In this experiment, two AE sensors were attached to the upper and lower ends of the back of samples. Moreover, Seven samples representing each of the wetting-drying group were selected for the microstructure and mineral composition analyses using (SEM) (TESCAN-VEGAILLMN Scanning Electron Microscope) and X-ray diffraction (Japanese TTR III Multifunctional X-ray Diffraction Instrument) respectively.

\section{Results and discussion}

\subsection{Effect of wetting-drying cycles on tensile strength of rock}

The stress-strain curves subject to different numbers of wetting-drying cycles are shown in Fig. 2. Representative and average values are shown in Fig. 3. The basic schematic diagram of Brazil split can be seen in Fig. 1b. According to the analytical solution of elastic mechanics of plane stress problem, the compressive stress at the center of the disk is only three times of the tensile stress, so the tensile failure of the sample is not the compression failure, and then the splitting tensile strength of the sample is calculated.

It can be seen that as the number of wetting-drying cycles increases, the stress-strain curve becomes more ductile, especially after 10 cycles. This indicates that after the repeated wetting-drying process, the stiffness of

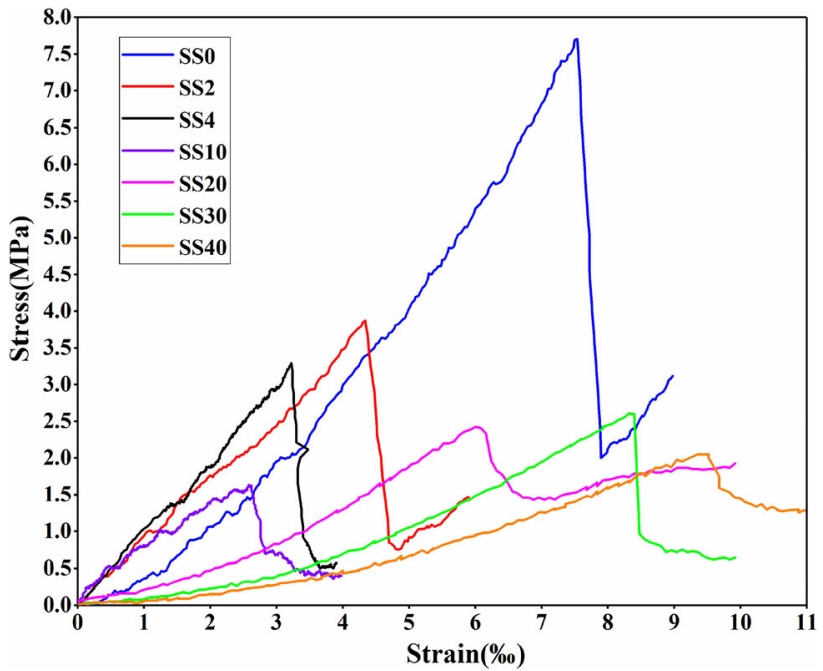

Fig. 2 Stress-strain curves of sandstone subjected to different numbers of wetting-drying cycles 


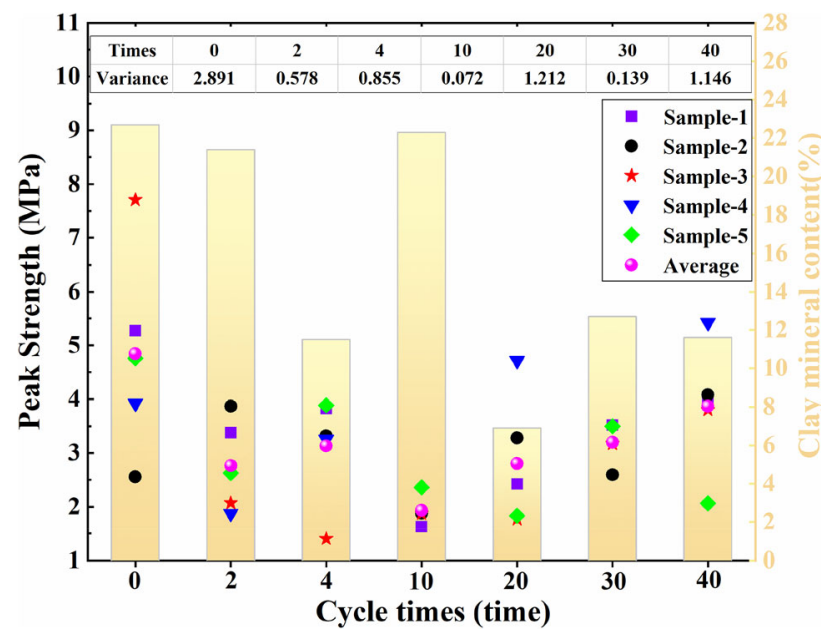

Fig. 3 Tensile strength and clay mineral content of sandstone subjected to different numbers of wetting-drying cycles

sandstone is significantly lower than that in the initial state. Moreover, it can be seen from Fig. 2 that after two wettingdrying cycles, the peak stress drops by about $50 \%$ compared with the initial state. After that, while the peak stress changes little with increasing number of cycles, the strain significantly increased. This phenomenon indicates that the first few wetting-drying cycles have a greater impact on the strength of rock, while the latter mainly affects the stiffness of rock. Furthermore, the tensile strength of all samples under different wetting-dry cycles was shown in Fig. 3 and Table 2. It demonstrates that the sandstone in natural state has the highest average tensile strength at $4.842 \mathrm{MPa}$ with the largest variance value at 2.891. Due to the influence of water during the wettingdrying cycles, the tensile strength of the samples is reduced, and the variance value is lower than that in the natural state. Moreover, it can be found that the tensile strength of the sandstone is not only affected by the number of wetting-drying cycles, but also closely related to the clay mineral content in the sandstone. For example, the tensile strength of samples subjected to 20,30 and 40 wettingdrying cycles is greater than the three groups of samples subjected to 10 cycles, which is mainly because of the low clay mineral content of these three groups. See Table 3 for

Table 2 Tensile strength of sandstone

\begin{tabular}{|c|c|c|c|c|c|c|c|}
\hline \multirow[t]{2}{*}{ Number of cycles } & \multicolumn{6}{|c|}{ Tensile strength (MPa) } & \multirow{2}{*}{$\frac{\tilde{\sigma}_{t 0}-\tilde{\sigma}_{\mathrm{t}(\mathrm{n})}}{\tilde{\sigma}_{t 0}} / n$} \\
\hline & Sample 1 & Sample 2 & Sample 3 & Sample 4 & Sample 5 & Average & \\
\hline 0 & 5.269 & 2.557 & 7.706 & 3.922 & 4.755 & 4.842 & 0 \\
\hline 2 & 3.377 & 3.867 & 2.066 & 1.873 & 2.627 & 2.762 & $21.48 \%$ \\
\hline 4 & 3.824 & 3.321 & 1.402 & 3.257 & 3.885 & 3.134 & $8.82 \%$ \\
\hline 10 & 1.622 & 1.878 & 1.868 & - & 2.361 & 1.932 & $6.01 \%$ \\
\hline 20 & 2.420 & 3.282 & 1.766 & 4.716 & 1.828 & 2.802 & $2.11 \%$ \\
\hline 30 & 3.519 & 2.593 & 3.174 & - & 3.496 & 3.200 & $1.13 \%$ \\
\hline 40 & 3.965 & 4.076 & 3.801 & 5.423 & 2.063 & 3.866 & $0.51 \%$ \\
\hline
\end{tabular}

Table 3 Mineral composition of sandstone samples

\begin{tabular}{|c|c|c|c|c|c|c|c|c|c|c|c|c|}
\hline \multirow[t]{2}{*}{ Sample number } & \multicolumn{8}{|c|}{ Mineral composition (\%) } & \multicolumn{4}{|c|}{ Relative content of clay minerals } \\
\hline & Quartz & Potash feldspar & Plagioclase & Siderite & Pyrite & $\begin{array}{l}\text { Iron } \\
\text { dolomite }\end{array}$ & Calcite & $\begin{array}{l}\text { Clay } \\
\text { mineral }\end{array}$ & $\mathrm{I} / \mathrm{S}$ & It & $\mathrm{K}$ & $\mathrm{C}$ \\
\hline SS0-3 & 60.5 & 0.5 & 0.4 & 13.8 & 1.0 & 1.1 & - & 22.7 & 13 & 31 & 56 & - \\
\hline SS2-4 & 78.4 & 0.2 & - & - & - & - & - & 21.4 & 11 & 30 & 59 & - \\
\hline SS4-1 & 73.1 & - & - & - & - & 15.4 & - & 11.5 & 16 & 50 & 34 & - \\
\hline SS10-3 & 66.8 & 0.2 & 0.4 & 6.5 & 3.8 & - & - & 22.3 & 10 & 33 & 57 & - \\
\hline SS20-3 & 88.2 & - & - & - & - & 3.3 & 1.6 & 6.9 & 14 & 14 & 72 & - \\
\hline SS30-5 & 76.2 & - & - & - & 1.6 & 9.5 & - & 12.7 & 9 & 21 & 27 & 43 \\
\hline SS40-5 & 73.6 & - & - & - & 3.5 & 8.9 & 2.4 & 11.6 & 11 & 32 & 57 & - \\
\hline
\end{tabular}

Note: $I / S$ refers to Aemon mixed layer, $I t$ refers to Illite, $K$ refers to Kaolinite, $C$ refers to Chlorite 
(a) Reduction in tensile strength caused by cumulative wetting-drying cycles

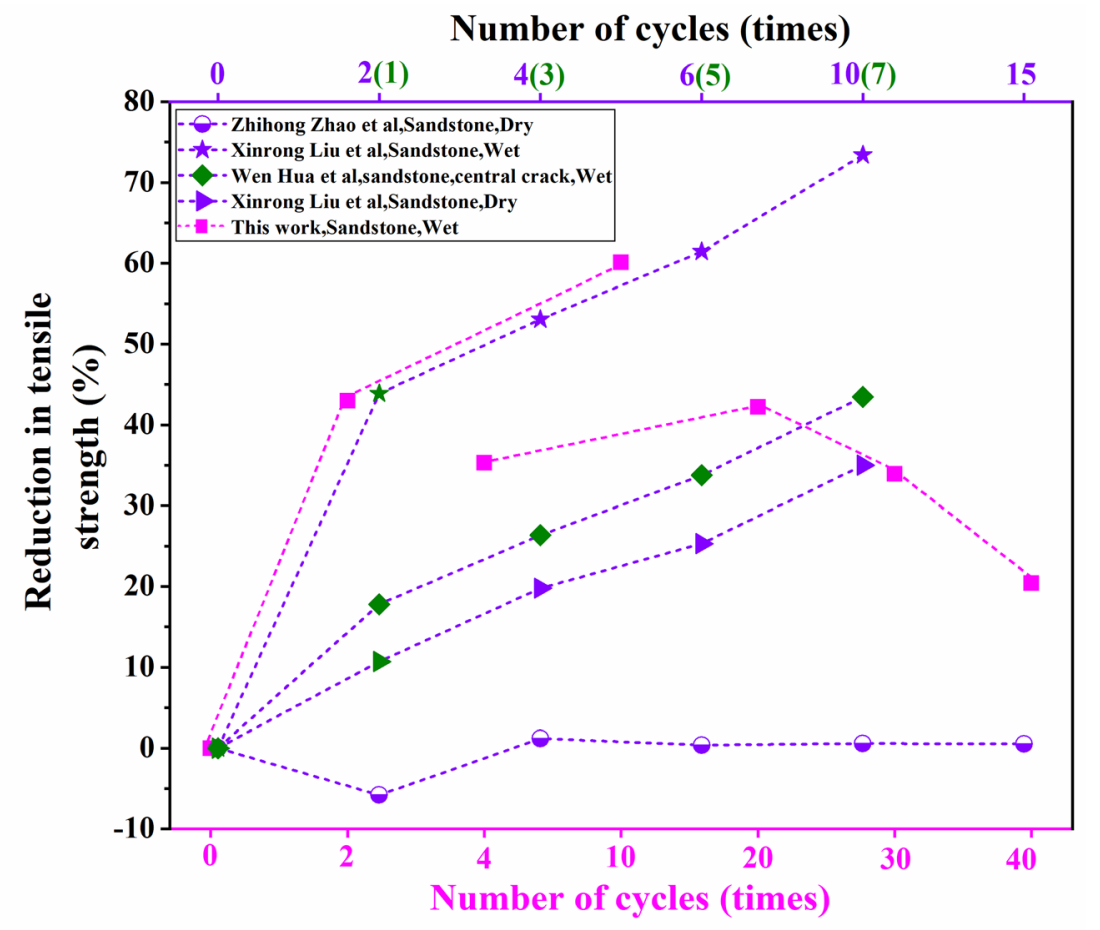

(b) Reduction in tensile strength caused by a single wetting-drying cycle

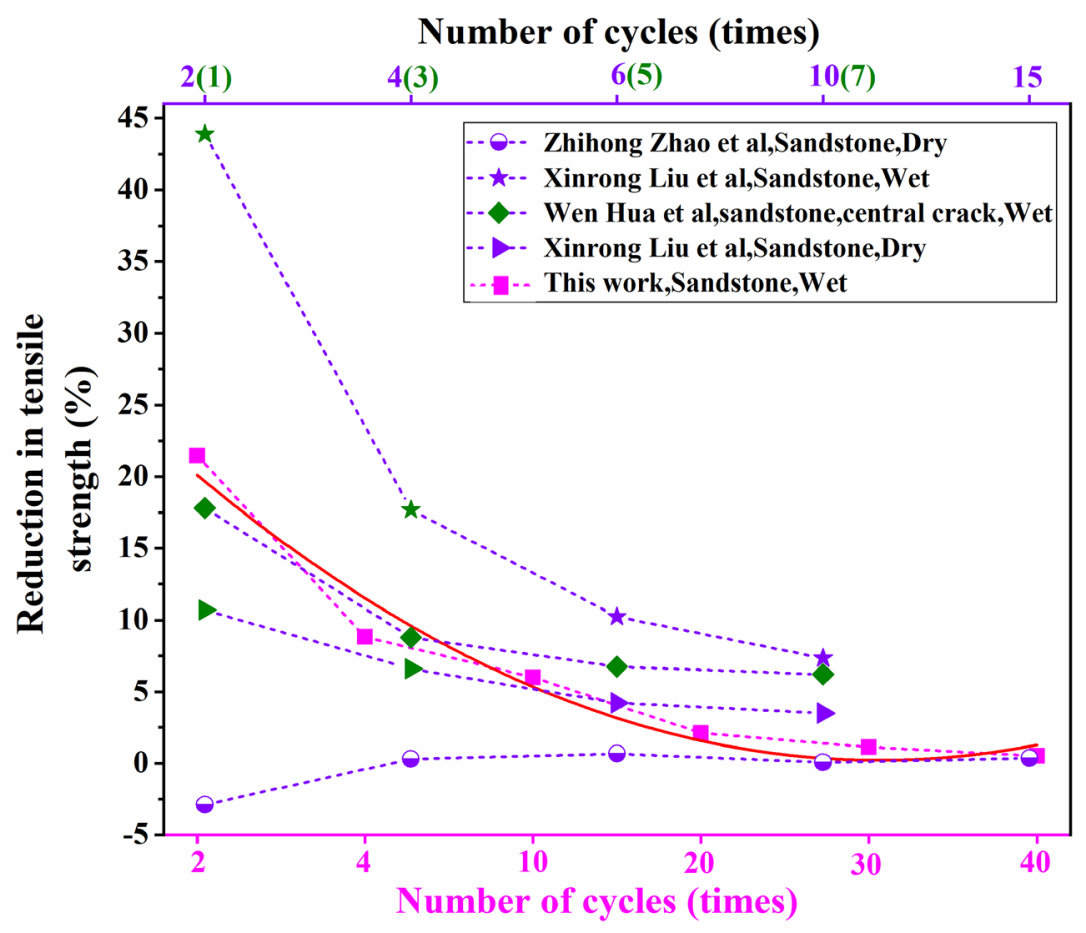

Fig. 4 Tensile strength reduction of sandstone subjected to different numbers of wetting-drying cycles

specific clay mineral content. At the same sampling location, the clay mineral composition of the sample is different. When the sample is cut into the standard test sample size, the dry and wet cycles are carried out under the same conditions. The clay content of the first three groups is high, and that of the last three groups is relatively low. 


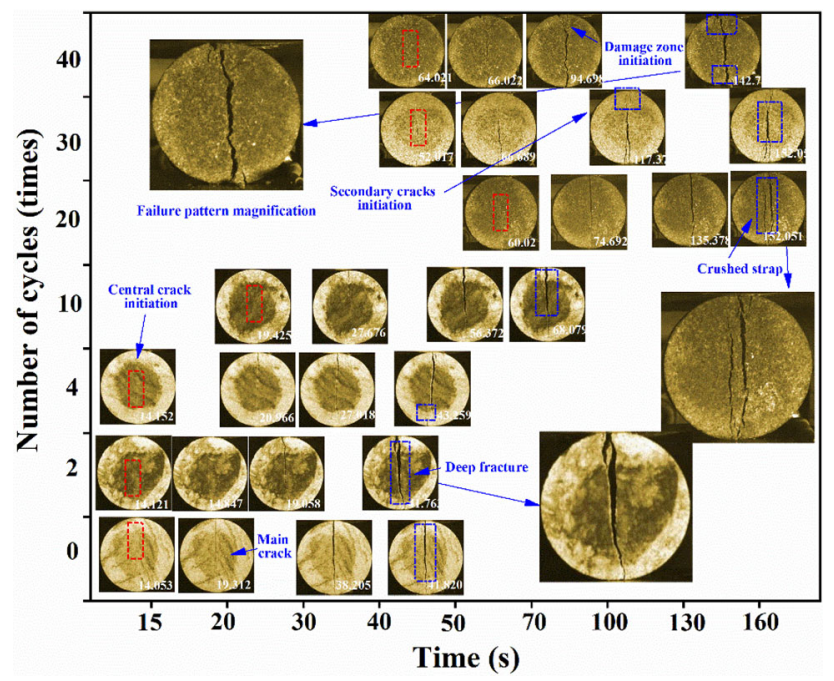

Fig. 5 Crack propagation process of sandstone subjected to different numbers of wetting-drying cycles

In addition, reduction in tensile strength of sandstone subjected to different number of wetting-drying cycles was shown in Fig. 4. Figure 4a presents the reduction in tensile strength caused by cumulative wetting-drying cycles, and Fig. $4 \mathrm{~b}$ presents the reduction in tensile strength caused by a single wetting-drying cycle. It can be seen from Fig. 4a that the reduction of tensile strength of sandstone with large clay content increases with the number of wettingdrying cycles, while that of sandstone with low clay mineral content is not. This is consistent with previous research results. For example, the number of wetting-drying cycles of sandstone with clay mineral content of less than $2 \%$ has little or negligible effect on tensile strength (Zhao et al. 2017a, b). However, for the sandstones containing clay minerals, the reduction in tensile strength increases with the number of wetting-drying cycles (Hua et al. 2015; Liu et al. 2016). Furthermore, the reduction in tensile strength caused by a single wetting-drying cycle is calculated using the following equation. That is, the reduction degree of average tensile strength of each time in 2 times, 4 times, 10 times, 20 times, 30 times and 40 times:

$\sigma=\frac{\overline{\sigma_{0}}-\overline{\sigma_{n}}}{\overline{\sigma_{0}}} \times 100 \% / n$

where $\sigma$ is the reduction in tensile strength, $\overline{\sigma_{0}}$ is the average tensile strength in nature, $\overline{\sigma_{n}}$ is the average tensile strength of sandstone subjected to $n$ times wetting-drying cycles. As shown in Fig. 4b, the average cycle strength of each group of samples decreased under different cycles. As the number of wetting-drying cycle increases, the effect of single wetting-drying cycle on tensile strength is get reduced until it becomes constant. Moreover, the effect of a single wetting-drying cycle on tensile strength can be fitted by a quadratic curve. (a) Time of crack initiation

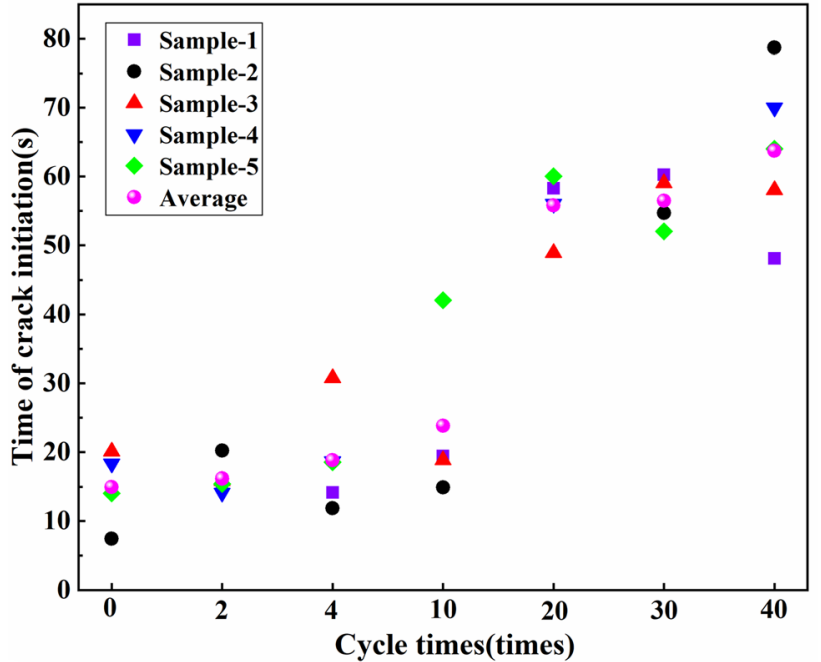

(b) Time of crack penetration

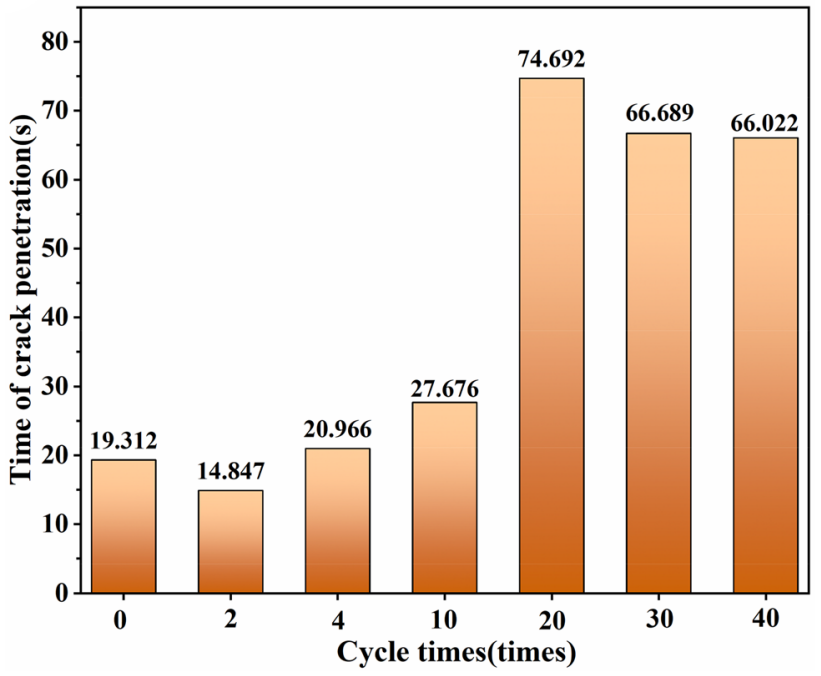

Fig. 6 Crack initiation and penetration time of sandstone subjected to different numbers of wetting-drying cycles

\subsection{Effect of wetting-drying cycles on crack propagation process}

In order to analyze in detail the effect of the number of wetting-drying cycles on crack propagation, the images on the front surface of specimens were captured using highspeed camera. The crack propagation process of sandstone with different wetting-drying cycles was shown in Fig. 5. From the perspective of qualitative analysis, it can be seen from Fig. 5 that the crack opening and penetration time is prolonged with the increase of wetting-drying cycles. This further indicates the great influence of the number of wetting-drying cycles on the stiffness of sandstone. In addition, as the number of wetting-drying cycles increases, 
(a)

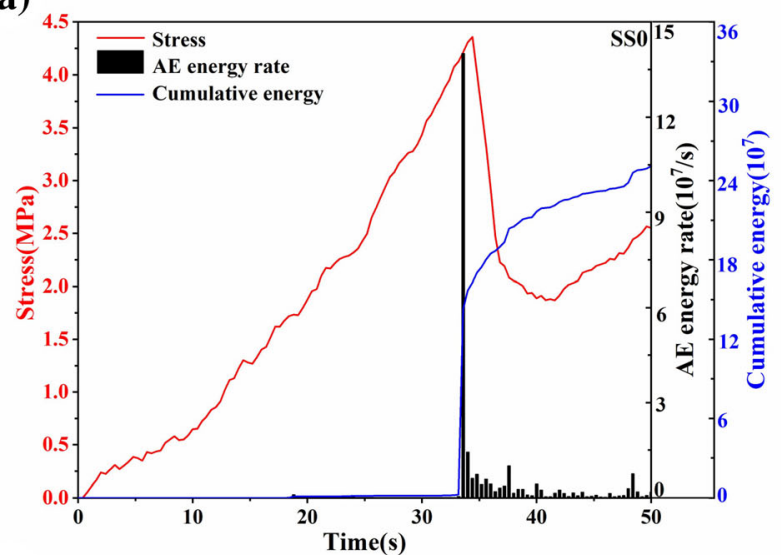

(b)

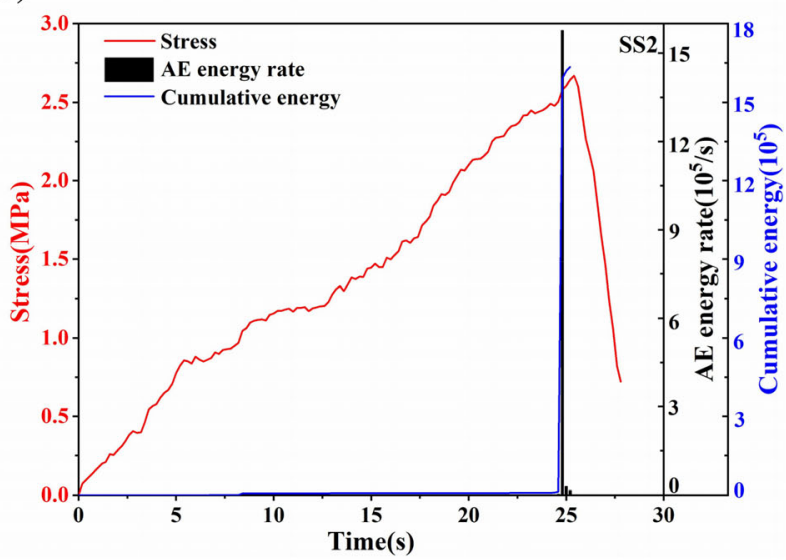

(c)

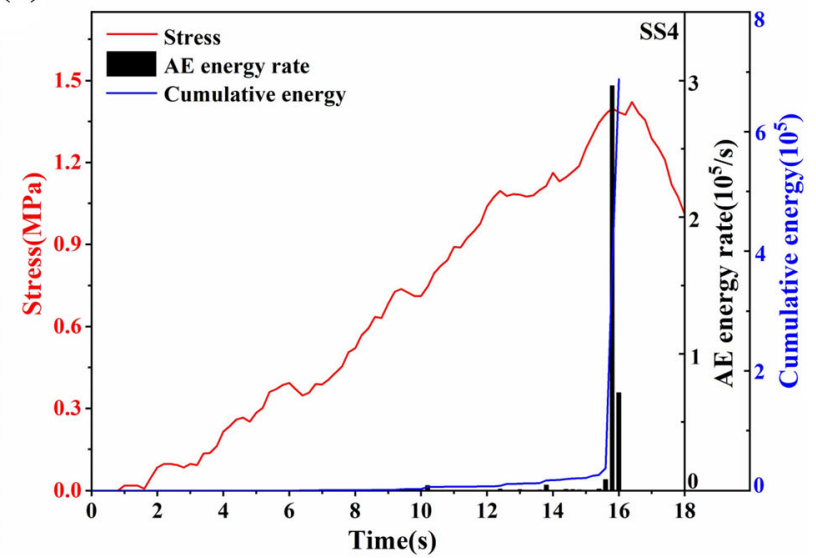

Fig. 7 AE characteristics of sandstone subjected to different numbers of wetting-drying cycles during the loading process (a-g represent sandstone specimens subjected to $0,2,4,10,20,30,40$ cycles, respectively)

besides the primary crack, secondary cracks also appear in the crack process. Moreover, the crack initiation and penetration time of all samples are counted in Fig. 6 which shows that as the number of wetting-drying cycle increases, the crack initiation time is delayed accordingly. (d)

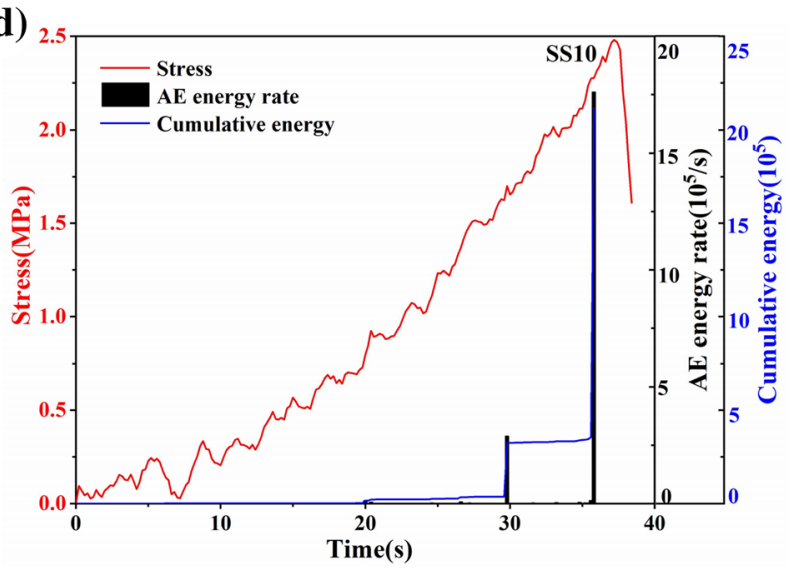

(e)

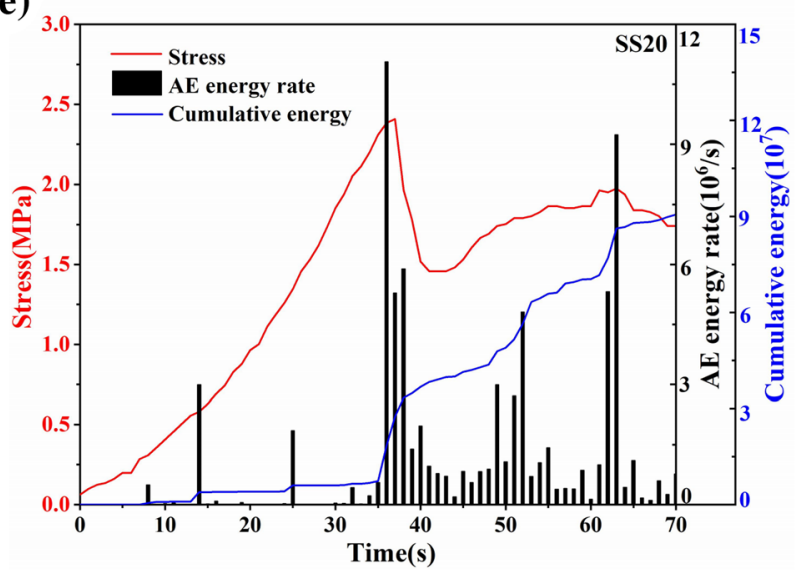

(f)

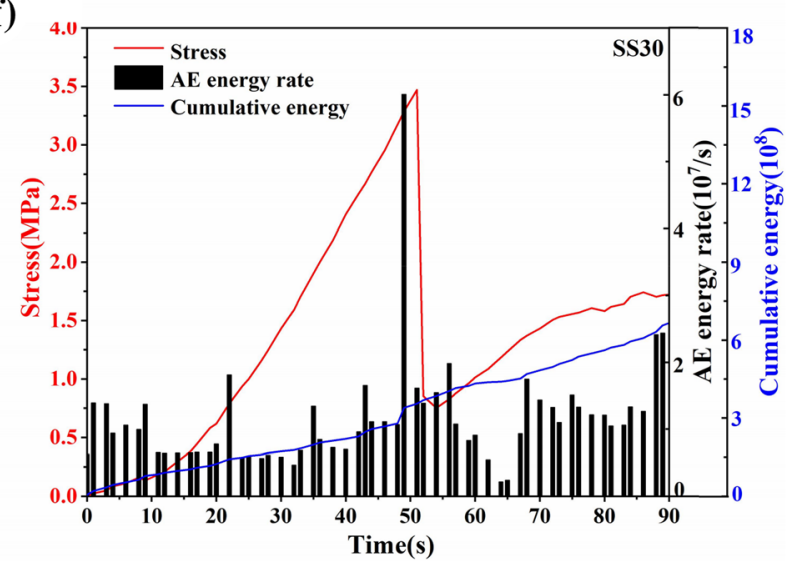

Fig. 7 continued

Meanwhile, it can be seen in Fig. 6b that the crack penetration time increases with the increase of wetting-drying cycles, which indicates that the rate of crack propagation becomes slower as the number of wetting-drying cycles increases. This is the time from the beginning of crack shooting by high-speed camera to the conversion of frame rate corresponding to the picture. This result only shows 
(g)

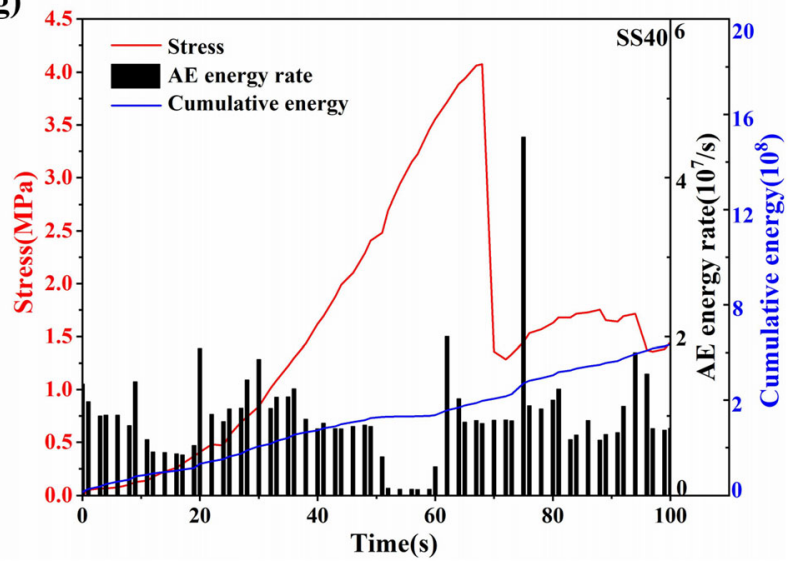

Fig. 7 continued

the influence of drying- wetting cycles on crack growth rate, and does not consider clay mineral content.

In addition, the $\mathrm{AE}$ energy rate and cumulative $\mathrm{AE}$ energy during the entire experiment was monitored. The variation of $\mathrm{AE}$ characteristics during the loading process was shown in Fig. 7. Similar to previous studies, the AE characteristics of sandstone throughout the experiment with respect to different wetting-drying cycles can be divided into four stages (Ranjith et al. 2008; Rodriguez and Celestino 2019; Song et al. 2019a, b). The first is the existing micro-crack or pore compaction stage. During this stage the corresponding acoustic emission energy is rare. As the number of wetting-drying cycle increases, this stage tends to be extended. The second is the elastic deformation stage, in which the corresponding acoustic emission energy increases gradually and slowly. This stage is also extended as the number of wetting-drying cycle increases. The third is the crack propagation stage, in which the corresponding acoustic emission event increases sharply due to rock rupture. The fourth is the post-peak stage. As the number of wetting-drying cycles increases, the acoustic emission energy of the sample at this stage also increases accordingly. This indicates that the wetting-drying cycle enhances the plasticity and ductility of sandstone.

\subsection{Effect of wetting-drying cycle on microstructure and strength weakening mechanisms}

During the wetting-drying cycle, the microstructure of the sample will be altered due to repeated water-rock interactions. Figure 8 presents the SEM images of the sandstone with different number of wetting-drying cycles. Table 3 is included with the mineralogy after cycling. Please refer to the group number. The right column in Fig. 8 shows the overall microstructure change for sandstone samples with clay minerals. It shows that as the number of wetting-dry cycle increases, there is no big change in large granular minerals such as quartz, but significant changes in clay mineral particles. Due to the action of water, the clay mineral particles gradually change from being massive, neat and dense to flat, muddy and honeycomb. The right side of Fig. 8 is a partially enlarged picture. It can be seen that more inter granular cracks appear as the number of wetting-drying cycle increases. Especially when the number of wetting-drying cycles is above 10, there are microcracks between almost every two sandstone grains, and inter granular pore increases obviously. In summary, with the increase of the number of wetting-drying cycles, the secondary fractures and micro fractures increase, the morphological characteristics and internal structure of sandstone change to a certain degree, and the microstructure of sandstone gradually changes from being neat and dense to rough and disordered, until it becomes muddy, loose and slice particle structure. In addition, with the increase of inter granular porosity, some interstitial fillings become muddy or flaky, and the cementation between particles weakens. Bigger pores in the sample surface develop into micro-cracks. At the macro level, it is reflected in the lower strength parameters of the sandstone, which is similar to the prior experimental study (Liu et al. 2018).

Previous studies have shown that the weakening mechanism of water on rock strength mainly includes fracture energy reduction, capillary tension decrease, pore pressure increase, fractional reduction, and chemical and corrosive deterioration. Regarding sandstone specimens in this experiment, the main tensile strength weakening mechanism is fraction reduction and physicochemical corrosion. It can be seen from the SEM of samples subjected to different wetting-drying cycles that as the number of wettingdrying cycle increases, the cementation between the particles weakens and the pores between the granularities increase, which seriously weakens the fractional effect. Moreover, it can be seen from Table 3 that after the sample undergoes the wetting-drying cycle, the feldspar minerals containing soluble ions such as potassium and sodium decreased or even disappeared due to hydrolysis reaction. In addition, the most important reason is that clay minerals such as montmorillonite and illite swell when they encounter water, and the original structure of sample is destroyed during repeated expansion to reduce its tensile strength.

\section{Conclusions}

This paper mainly discussed the effect of cyclic wettingdrying on tensile mechanical behavior of sandstone through experiment. First, a total of 35 sandstone samples 

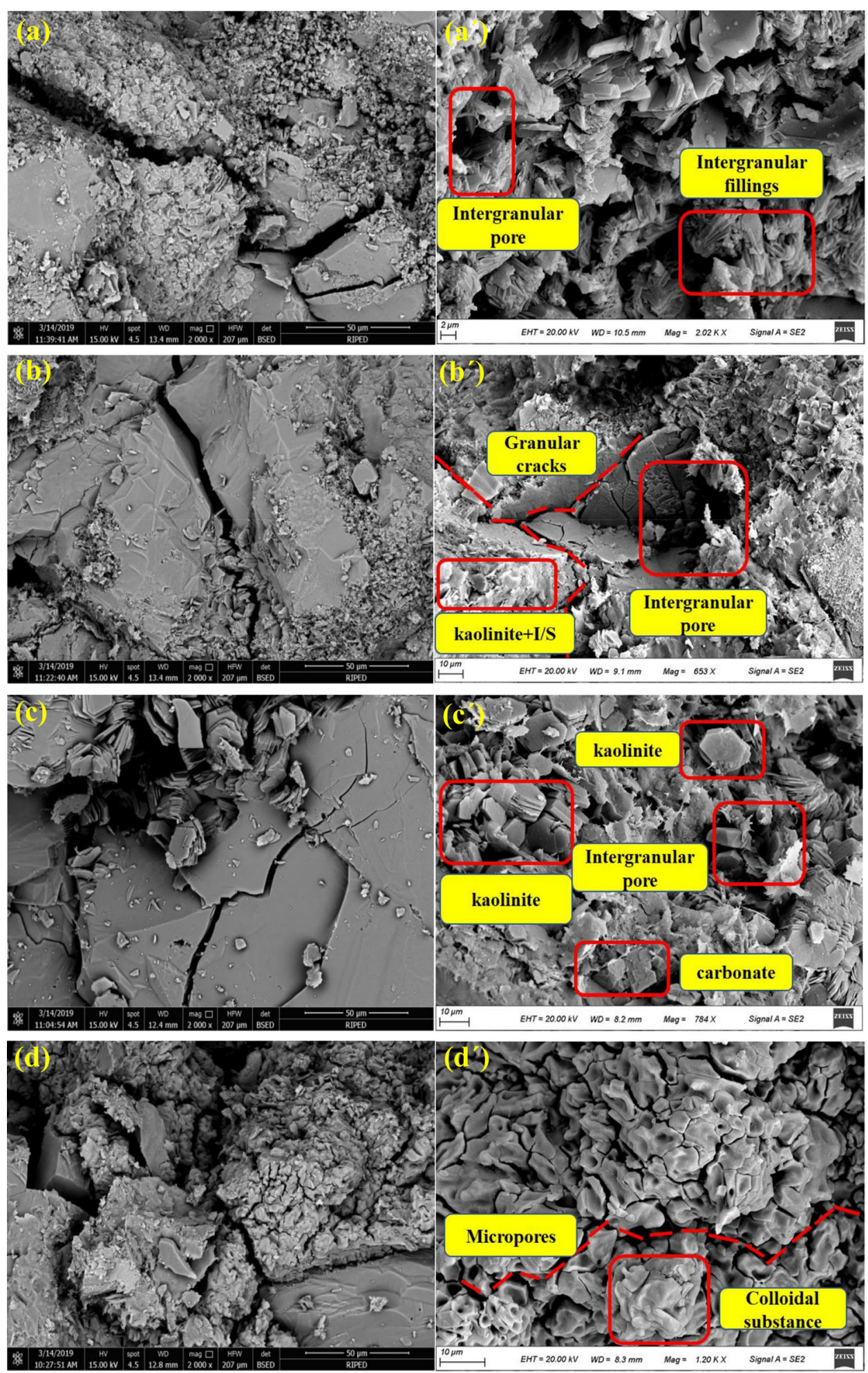

Fig. 8 SEM images of sandstone subjected to different numbers of wetting-drying cycles (a-g represent sandstone specimens subjected to $0,2,4$, $10,20,30,40$ cycles, respectively) 

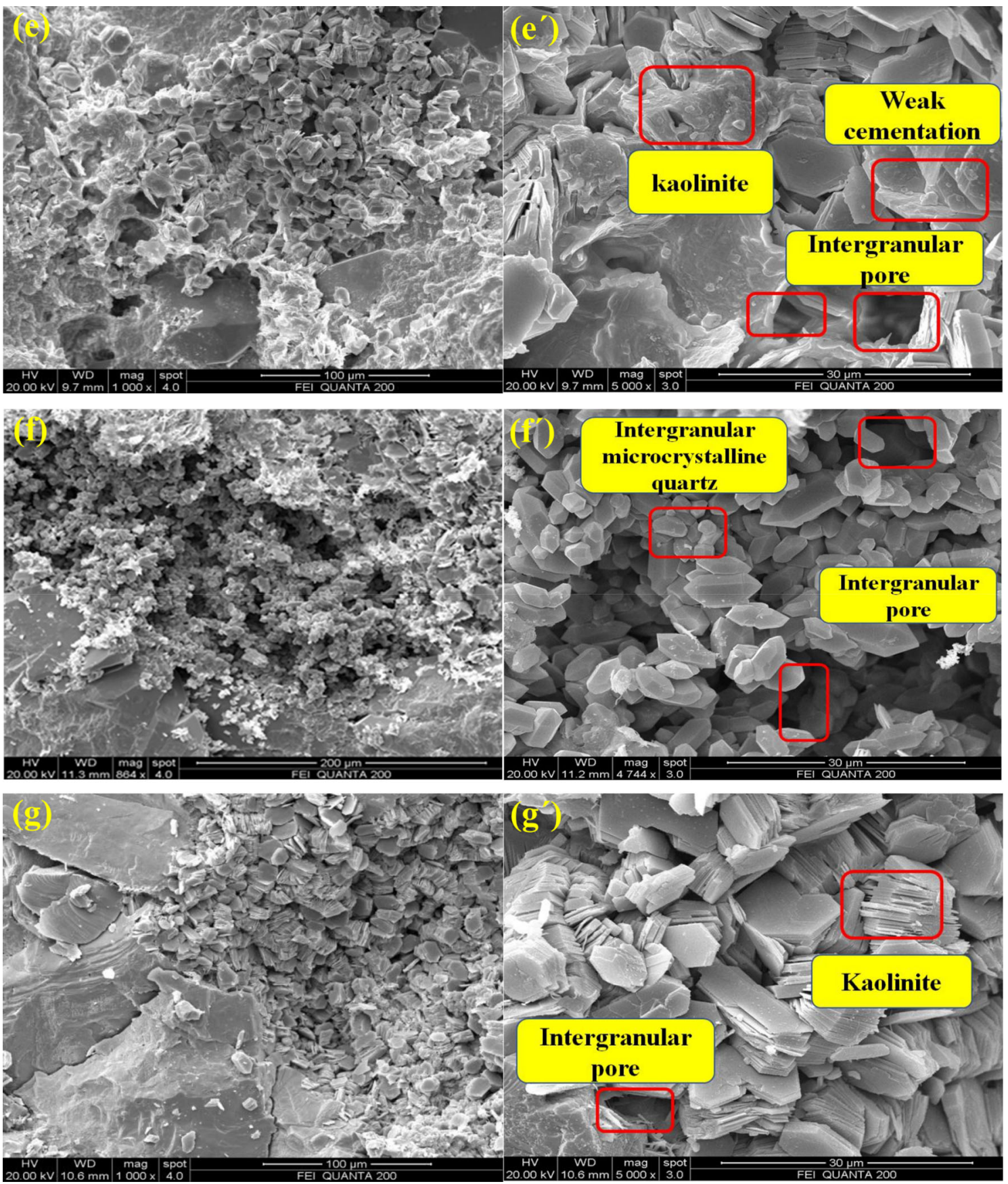

Fig. 8 continued

were divided into 7 groups, each of which was subjected to different numbers of artificial wetting-drying cycles. Afterwards, the tensile strength of the sandstone specimens was measured by the Brazilian disc tests. Moreover, the crack propagation process and acoustic emission characteristics were obtained through high-speed cameras and acoustic emission monitoring systems, respectively. Based on the current experimental results, main conclusions were obtained as follows.
(1) The tensile strength of the sandstone subject to different numbers of wetting-drying cycles is observably reduced by $24 \%-60 \%$. The extent of reduction in tensile strength is not only related to the number of wetting-drying cycle, but also closely related to the clay mineral content of the specimens. Moreover, as the number of wetting-drying cycle increases, the effect of single wetting-drying cycle on tensile strength is get reduced until it becomes constant. 
When sandstone specimens were subjected to 2,4 , $10,20,30,40$ times of wetting-drying cycle, the tensile strength reductions caused by a single cycle are $21.48 \%, 8.82 \%, 6.01 \%, 2.11 \%, 1.13 \%$ and $0.51 \%$, respectively.

(2) With the increase in number of wetting-drying cycle, the crack initiation and penetration time is prolonged gradually. Meanwhile, stress-strain curves show that the stiffness also remarkably decreases with the increase in number of wetting-drying cycle. These indicate that cyclic wetting-drying weakens the stiffness and enhances the ductility of sandstone. In addition, the acoustic emission characteristics during the experiment further confirmed this phenomenon.

(3) Regarding sandstones containing clay minerals in this work, the main weakening mechanisms are frictional reduction, chemical and corrosive deterioration, including the swelling of clay minerals.

Acknowledgements Funding for this work was provided by Natural Science Foundation of China (41941018; 41402273), the Yue Qi Scholar Program of China University of Mining and Technology. The authors wish to thank the reviewers for careful and constructive suggestions.

\section{Compliance with ethical standards}

Conflict of interest The authors declared that they have no conflict of interest to this work. We declare that we do not have any commercial or associative interest that represents a conflict of interest in connection with the work submitted.

Open Access This article is licensed under a Creative Commons Attribution 4.0 International License, which permits use, sharing, adaptation, distribution and reproduction in any medium or format, as long as you give appropriate credit to the original author(s) and the source, provide a link to the Creative Commons licence, and indicate if changes were made. The images or other third party material in this article are included in the article's Creative Commons licence, unless indicated otherwise in a credit line to the material. If material is not included in the article's Creative Commons licence and your intended use is not permitted by statutory regulation or exceeds the permitted use, you will need to obtain permission directly from the copyright holder. To view a copy of this licence, visit http://creativecommons. org/licenses/by/4.0/.

\section{References}

An R, Kong L, Li C et al (2020) Strength attenuation and microstructure damage of granite residual soil in hot and rainy climate. Chin J Rock Mech Eng 39(09):1902-1911. https://doi. org/10.13722/j.cnki.jrme.2020.0073

ASTM (2008) Standard test method for splitting tensile strength of intact rock core specimens. ASTM Int, West Conshohocken, USA

Baud P, Zhu W, Wong TF (2000) Failure mode and weakening effect of water on sandstone. J Geophys Res Solid Earth 105(B7):16371-16389. https://doi.org/10.1029/2000JB900087
Cherblanc F, Berthonneau J, Bromblet P et al (2016) Influence of water content on the mechanical behaviour of limestone: role of the clay minerals content. Rock Mech Rock Eng 49:2033-2042. https://doi.org/10.1007/s00603-015-0911-y

Doostmohammadi R, Moosavi M, Mutschler T et al (2009) Influence of cyclic wetting and drying on swelling behavior of mudstone in south west of Iran. Environ Geol 58:999. https://doi.org/10.1007/ s00254-008-1579-3

Duda M, Renner J (2013) The weakening effect of water on the brittle failure strength of sandstone. Geophys J Int 192(3):1091-1108. https://doi.org/10.1093/gji/ggs090

Eang KE, Igarashi T, Kondo M et al (2018) Groundwater monitoring of an open-pit limestone quarry: water-rock interaction and mixing estimation within the rock layers by geochemical and statistical analyses. Int J Min Sci Technol 28(06):849-857. https://doi.org/10.1016/j.ijmst.2018.04.002

Fu Y, Wang Z, Liu X et al (2017) Study on meso damage evolution and macro deterioration of sandstone under dry wet cycle. Chin J Geotech Eng 39(09):1653-1661. https://doi.org/10.11779/ CJGE201709013

Hale PA, Shakoor A (2003) A laboratory investigation of the effects of cyclic heating and cooling, wetting and drying, and freezing and thawing on the compressive strength of selected sandstones. Environ Eng Geosci 9(2):117-130. https://doi.org/10.2113/9.2. 117

Han T, Shi J, Chen Y (2016) Experimental study on the correlation between fracture toughness and strength characteristics of sandstone under freeze-thaw cycles and dry wet cycles. J Hydraul Eng 37(4):348-359. https://doi.org/10.13243/j.cnki.slxb. 20171191

Hua W, Dong S, Li Y et al (2015) The influence of cyclic wetting and drying on the fracture toughness of sandstone. Int J Rock Mech Min. https://doi.org/10.1016/j.ijrmms.2015.06.010

Huang S, Xia K, Yan F et al (2010) An experimental study of the rate dependence of tensile strength softening of Longyou sandstone. Rock Mech Rock Eng 43(6):677-683. https://doi.org/10.1007/ s00603-010-0083-8

ISRM (1978) Suggested methods for determining tensile strength of rock materials. Int J Rock Mech Min 15(3):99-103

Karakul H, Ulusay R (2013) Empirical correlations for predicting strength properties of rocks from P-wave velocity under different degrees of saturation. Rock Mech Rock Eng 46:981-999. https:// doi.org/10.1007/s00603-012-0353-8

Liu X, Wang Z, Fu YF et al (2016) Macro/microtesting and damage and degradation of sandstones under dry-wet cycles. Adv Mater Sci Eng 2016:1-16. https://doi.org/10.1155/2016/7013032

Liu X, Jin M, Li D et al (2018) Strength deterioration of a Shaly sandstone under dry-wet cycles: a case study from the Three Gorges Reservoir in China. Bull Eng Geol Environ 77:1607-1621. https://doi.org/10.1007/s10064-017-1107-3

Liu K, Ye W, Gao H et al (2020) Multi scale effect of mechanical property deterioration of expansive soil under dry and wet environment. Chin J Rock Mech Eng 39(10):2148-2159. https:// doi.org/10.13722/j.cnki.jrme.2020.0170

Ma Q, Yu P, Yuan P et al (2018) Experimental study on the influence of dry wet cycle on creep characteristics of deep siltstone. Chin J Rock Mech Eng 37(03):593-600. https://doi.org/10.13722/j. cnki.jrme.2017.0711

Mann RL, Fatt I (1960) Effect of pore fluids on the elastic properties of sandstone. Geophysics 25(2):433-444

Momeni A, Hashemi SS, Khanlari GR et al (2017) The effect of weathering on durability and deformability properties of granitoid rocks. Bull Eng Geol Environ 76(3):1-13. https://doi.org/ 10.1007/s10064-016-0999-7

Özbek A (2014) Investigation of the effects of wetting-drying and freezing-thawing cycles on some physical and mechanical 
properties of selected ignimbrites. Bull Eng Geol Environ 73(2):595-609. https://doi.org/10.1007/s10064-013-0519-y

Pudlo D, Reitenbach V, Albrecht D et al (2012) The impact of diagenetic fluid-rock reactions on Rotliegend sandstone composition and petrophysical properties (Altmark area, central Germany). Environ Earth Sci 67(2):369-384. https://doi.org/10. 1007/s12665-012-1723-y

Ranjith PG, Jasinge D, Song JY et al (2008) A study of the effect of displacement rate and moisture content on the mechanical properties of concrete: use of acoustic emission. Mech Mater 40(6):453-469. https://doi.org/10.1016/j.mechmat.2007.11.002

Rodriguez P, Celestino TB (2019) Application of acoustic emission monitoring and signal analysis to the qualitative and quantitative characterization of the fracturing process in rocks. Eng Fract Mech 210:54-69. https://doi.org/10.1016/j.engfracmech.2018. 06.027

Song C, Ji H, Liu Z et al (2019b) Experimental study on acoustic emission characteristics of weakly cemented rock under dry wet cycle. J Min Saf Eng 36(04):812-819. https://doi.org/10.13545/j. cnki.jmse.2019.04.021

Song Y, Zhang L, Ren J et al (2019a) Study on dry wet cycle damage characteristics of weakly cemented sandstone based on nuclear magnetic resonance. Chin J Rock Mech Eng 38(04):825-831. https://doi.org/10.13722/j.cnki.jrme.2018.1412

Vasarhelyi B, Van P (2006) Influence of water content on the strength of rock. Nature 184(12):70-74. https://doi.org/10.1016/j.enggeo. 2005.11.011

Wong LNY, Jong MC (2014) Water saturation effects on the brazilian tensile strength of gypsum and assessment of cracking processes using high-speed video. Rock Mech Rock Eng 47(4):1103-1115. https://doi.org/10.1007/s00603-013-0436-1

Wong LNY, Maruvanchery V, Liu G (2015) Water effects on rock strength and stiffness degradation. Acta Geotech 11(4):1-25. https://doi.org/10.1007/s11440-015-0407-7
Wu J, Feng M, Yu B et al (2018) Experimental investigation on dilatancy behavior of water-saturated sandstone. Int J Min Sci Technol 28(2):323-329. https://doi.org/10.1016/j.ijmst.2017.09. 003

Yang R, Li Y, Guo D et al (2017) Failure mechanism and control technology of water-immersed roadway in high-stress and soft rock in a deep mine. Int $\mathrm{J}$ Min Sci Technol 27(2):245-252. https://doi.org/10.1016/j.ijmst.2017.01.010

Yang X, Wang J, Zhu C et al (2019) Effect of wetting and drying cycles on microstructure of rock based on SEM. Environ Earth Sci 78(6):1-10. https://doi.org/10.1007/s12665-019-8191-6

Yilmaz I (2010) Influence of water content on the strength and deformability of gypsum. Int J Rock Mech Min 47(2):342-347. https://doi.org/10.1016/j.ijrmms.2009.09.002

Zhao Z, Yang J, Zhang D et al (2017a) Effects of wetting and cyclic wetting-drying on tensile strength of sandstone with a low clay mineral content. Rock Mech Rock Eng 50:485-491. https://doi. org/10.1007/s00603-016-1087-9

Zhao Z, Yang J, Zhou D et al (2017b) Experimental investigation on the wetting-induced weakening of sandstone joints. Eng Geol 225:61-67. https://doi.org/10.1016/j.enggeo.2017.04.008

Zhou Z, Cai X, Cao W et al (2016) Influence of water content on mechanical properties of rock in both saturation and drying processes. Rock Mech Rock Eng 49(8):3009-3025. https://doi. org/10.1007/s00603-016-0987-Z

Zhou Z, Cai X, Ma D et al (2018a) Effects of water content on fracture and mechanical behavior of sandstone with a low clay mineral content. Eng Fract Mech 193:47-65. https://doi.org/10. 1016/j.engfracmech.2018.02.028

Zhou Z, Cai X, Ma D et al (2018b) Dynamic tensile properties of sandstone subjected to wetting and drying cycles. Constr Build Mater 182:215-232. https://doi.org/10.1016/j.conbuildmat.2018. 06.056 